\title{
MENGUKUR EFISIENSI KINERJA PENGIRIMAN FREEZE KONTAINER DENGAN MENGGUNAKAN KPI BALANCE SCORECARD DI PT. RUKMA PADAYA TRANS
}

\author{
Muhammad Syaifuddin ${ }^{1}$, Harunur Rosyid ${ }^{2}$ \\ ${ }^{1}$ PT Rukma Padya Trans Container \\ ${ }^{2}$ Teknik Informatika, Universitas Muhammadiyah Gresik \\ Email:saifuddinifud@gmail.com
}

\begin{abstract}
ABSTRAK
Pengiriman barang di PT. Rukma Padaya Trans Container masih terdapat kendala antara lain jumlah pesanan pengiriman yang menumpuk, lamanya proses pengecekan kondisi container dan lain-lain yang menyebabkan keterlambatan dan penurunan kualitas pengiriman sehingga container tidak dapat sampai tepat waktu atau datang kurang optimal. kondisi. Untuk menghindari keterlambatan pengiriman barang, ada beberapa solusi yang dapat digunakan agar barang dapat mengirimkan peti kemas tepat waktu. Diantaranya, kontainer yang memiliki kredibilitas dan elektabilitas yang baik di mata konsumen. Terkait masalah di atas, dapat dianalisis dengan menggunakan beberapa model pengukuran kinerja, salah satunya dengan metode Balance Scorecard. Menurut Handayani (2011). Balanced Scorecard dimulai dengan visi dan misi yang merupakan ukuran kinerja untuk empat perspektif yang berbeda, yaitu perspektif pelanggan, finansial.
\end{abstract}

Kata Kunci: Mengukur Efisiensi Kinerja, Balanced Scorecard

\section{Pendahuluan}

\subsection{Latar Belakang Masalah}

Berdirinya Hamparan segara Niaga Group (HSN Group) dilatar belakangi atas dasar semakin meningkatnya kebutuhan akan adanya pengangkutan barang-barang untuk di distribusikan ke seluruh indonesia, yang bergerak di bidang transportasi, baik lokal maupun internasional. Salah satu upaya untuk memantau kinerja dan menjaga konsistensinya dalam menjalankan tugas adalah dengan melakukan pengukuran kinerja (Taruna and Ciptomulyono 2011).

Pengiriman barang dalam container masih terjadi kendala - kendala yang menyebabkan keterlambatan pengiriman sehingga container tersebut tidak bisa datang tepat waktu. Menumpuknya pengiriman Kontainer dan lamanya pengecekan kondisi container biasanya menjadi salah satu factor keterlambatanya pengiriman barang di Freze container. Fokus penelitian ini adalah mengukur efisiensi kinerja pengiriman freeze kontainer di Pt. Rukma Padaya Trans khususnya dititik beratkan pada perspektif non-finansial, yaitu perspektif pelanggan, proses bisnis internal, serta pembelajaran dan pertumbuhan pada perusahaan tersebut, yang berorientasi kepada pelayanan masyarakat dan bukan sebagai perusahaan yang berorientasi kepada keuntungan Perusahaan.

Terkait dengan permasalahan diatas, dapat dianalisis menggunakan beberapa model pengukuran kinerja, salah satunya dengan metode Balance Scorecard. Balanced Scorecard dimulai dengan visi dan misi yang menjadi ukuran kinerja untuk empat perspektif yang berbeda, serta memiliki kerangka kerja yang komprehensif untuk menerjemahkan visi dan misi serta strategi perusahaan dalam seperangkat ukuran kinerja yang terpadu, tersusun dalam empat perspektif yaitu perspektif pelanggan, perspektif keuangan, perspektif proses internal dan perspektif pembelajaran dan pertumbuhan. Dari permasalahan diatas kemudian dibuatkanlah sistem yang mampu mengukur kinerja dari pengiriman container.

Dengan dibuatkanya sistem untuk mengukur kinerja pengiriman di PT Rukma Pandaa Trans diharapkan memberikan rekomendasi terhadap perusahaan terkait bagaimana mengukur kinerja karyawan maupun unit kerjanya sehingga proses 
INDEXIA: Informatic and Computational Intelegent Journal

Muhammad Syaifuddin, Harunur Rosyid

Mengukur Efisiensi Kinerja Pengiriman Freeze Kontainer Dengan Menggunakan Kpi Balance

Scorecard Di Pt. Rukma Padaya Trans

evaluasi kinerja tahunan akan lebih efektif

dan efisien karna melihat dari hasil penilaian

kinerja di sistem tersebut.

\subsection{Rumusan Masalah}

Adapun rumusan masalahnya adalah "Bagaimana cara mengukur efisiensi kinerja pengiriman freeze container di PT Rukma Padaya Trans.

\subsection{Tujuan Penelitian}

Tujuan penelitian ini adalah mengukur efisiensi kinerja dari pengiriman container di PT. Rukma Padaya Trans.

\section{Landasan Teori}

\subsection{Tinjauan Pustaka}

Singgih, Octavia et al. (2004)

Mengevaluasi Pengukuran Dan Analisa Kinerja Dengan Metode Balanced Scorecard Di PT."X". Penelitian ini dilakukan untuk mengukur dan menganalisa kinerja di PT."X" dengan menggunakan metode Balanced Scorecard. Penelitian ini dilakukan karena sistem pengukuran yang dipakai selama ini hanya mengukur kinerja dari financial perspective. Hasil analisa menunjukkan adanya peningkatan kinerja perusahaan pada seluruh perspective kecuali pada internal business process perspective yang menunjukkan kestabilan kinerja pada level yang buruk. Sehingga untuk dapat meningkatkan kinerja perusahaan secara keseluruhan dilakukan dengan meningkatkan penyelesaian order tepat waktu dan menurunkan \% rata-rata produk cacat. Kedua hal tersebut dapat dicapai dengan semakin meningkatkan kinerja pemenuhan target, karena ketiga ukuran hasil tersebut memiliki bobot yang paling besar.

$$
\text { Hanuma and Kiswara (2011) }
$$

Menganalisis Balance Scorecard Sebagai Alat Pengukur Kinerja Perusahaan (Studi Kasus pada PT Astra Honda Motor). Penelitian dilakukan dengan menggunakan data tahun 2005-2006 pada PT Astra Honda Motor untuk menganalisis perspektif keuangan, sedangkan untuk perspektif lainnya dilakukan analisis melalui perhitungan kuesioner. Populasi dalam

penelitian ini adalah pelanggan dan karyawan PT Astra Honda Motor, sedangkan sample yang diambil masing-masing adalah 100 responden untuk karyawan dan 100 responden untuk pelanggan. Kuesioner tersebut telah diuji validitas dan reliabilitasnya. Indicator yang digunakan dalam penelitian ini terdiri dari ROI, profit margin, operating ratio, kepuasan pelanggan, inovasi, dan kepuasan karyawan. Dari hasil analisis yang telah dilakukan, dapat diketahui bahwa kinerja PT Astra Honda Motor secara keseluruhan sudah cukup baik.

Authoni and Suryani

Mengevaluasi Purwarupa Performance Dashboard Untuk Membantu Analisis Diri Perguruan Tinggi (PT) Berdasarkan Key Performance Indicators (KPI) Studi Kasus : PT X. Dashboard merupakan suatu alat yang dapat membantu pipmpinan perguruan tinggi mengevaluasi kinerja organisasisnya dengan menyajikan informasi key performance indicators (KPI) dalam bentuk antar muka visual secara sekilas dalam layar,sehingga data dapat dianalisa dengan lebih efektif, efesien, dan komprehensif.

\subsection{Pengertian Efisiensi}

Menurut Sunarto and Hasibuan (2007) efisiensi yaitu biaya produksi dan menciptakan nilai lebih bagi konsumen.

Balanced Scorecard lebih dari sekedar sistem pengukuran taktis atau operasional. Perusahaan yang inovatif menggunakan scorecard sebagai system manajemen strategis, untuk mengelola strategi jangka panjang dan menghasilkan proses manajemen seperti, Memperjelas dan menerjemahkan visi dan strategi, Mengkomunikasikan dan mengkaitkan berbagai tujuan dan ukuran strategis, Merencanakan, menetapkan sasaran, 
INDEXIA: Informatic and Computational Intelegent Journal

Muhammad Syaifuddin, Harunur Rosyid

Mengukur Efisiensi Kinerja Pengiriman Freeze Kontainer Dengan Menggunakan Kpi Balance

Scorecard Di Pt. Rukma Padaya Trans

dan menyelaraskan berbagai inisiatif

strategis, Meningkatkan umpan balik

dan pembelajaran strategis dengan

komputer untuk memudahkan pekerjaan atau tugas-tugas tertentu seperti penerapan, penggunaan dan penambahan data yang dibutuhkan.

\subsection{Pengertian Pengukuran Kinerja}

Menurut Hanuma and Kiswara (2011) pengukuran kinerja adalah tindakan pengukuran yang dapat dilakukan terhadap berbagai aktifitas dalam rantai nilai yang ada pada perusahaan. Hasil pengukuran tersebut kemudian digunakan sebagai umpan balik yang akan memberikan informasi tentang prestasi pelaksanaan suatu rencana dan titik dimana perusahaan memerlukan penyesuaian atas aktivitas perencanaan dan pengendalian tersebut. Pengukuran kinerja mempunyai tujuan pokok yaitu memotivasi karyawan dalam mencapai sasaran organisasi dan dalam mematuhi standar perilaku yang telah ditetapkan sebelumnya, agar membuahkan tindakan dan hasil yang diinginkan.

\subsection{Pengertian Key Performance Indikator}

Menurut Authoni and Suryani (2014) Key Performance Indicators (KPIs) merupakan indikator utama dari kinerja proses yang dijalankan organisasi. Mengidentifikasi dan memonitor indikator kinerja utama adalah bagian penting untuk administrasi perguruan tinggi. Fungsi dasar dari indikator kinerja adalah untuk membantu dalam menentukan seberapa baik perguruan tinggi/fakultas/program studi telah mencapai tujuan masing-masing. Key Performance Indicator (KPI) yang diidentifikasikan terdiri dari KPI strategi, KPI proses, dan KPI kapabilitas yang merupakan hasil dari identifikasi terhadap stakeholder requirements serta tujuan perusahaan.

Menurut Henderi, Rahayu et al. (2015) Key performance indicators (kpi) adalah metrik finansial ataupun non-finansial yang digunakan untuk membantu suatu organisasi menentukan dan mengukur kemajuan terhadap sasaran organisasi. KPI

digunakan dalam intelijen bisnis / business intelligence (BI) untuk menilai keadaan kini suatu bisnis dan menentukan suatu tindakan terhadap keadaan tersebut. KPI sering digunakan untuk menilai aktivitas-aktivitas yang sulit diukur seperti keuntungan pengembangan kepemimpinan, perjanjian, layanan, dan kepuasan. KPI umumnya dikaitkan dengan strategi organisasi yang contohnya diterapkan oleh teknik-teknik seperti kartu skor berimbang (BSC, balanced scorecard.

\subsection{Pengertian balanced scorecard (BSC)}

Menurut Hamzah, Suyoto et al. (2015) Balanced scorecard merupakan suatu sistem manajemen, pengukuran, danpengendalian yang secaracapat, tepat, dan komperhensif dapat memberikan kepada manajer tentang performance bisnis. Menurut (Singgih, Octavia et al. 2004) merupakan salah satu metode pengukuran dan manajemen performance untuk faktor internal dan eksternal dari suatu perusahaan.

Menurut Hanuma and Kiswara (2011) Balanced Scorecard merupakan suatu alat pengukur kinerja perusahaan yang mengukur kinerja perusahaan secara keseluruhan, baik secara keuangan maupun nonkeuangan dengan menggunakan empat perspektif yaitu, perspektif keuangan, perspektif pelanggan, perspektif bisnis internal, dan perspektif pertumbuhan dan pembelajaran

Dengan Balanced Scorecard, tujuan suatu perusahaan tidak hanya dinyatakan dalam ukuran keuangan saja, melainkan dinyatakan dalam ukuran dimana perusahaan tersebut menciptakan nilai terhadap pelanggan yang ada pada saat ini dan akan datang, dan bagaimana perusahaan tersebut harus meningkatkan kemampuan internalnya termasuk investasi pada manusia, sistem, dan prosedur yang dibutuhkan untuk memperoleh kinerja yang lebih baik di masa mendatang. Melalui Balanced Scorecard diharapkan bahwa pengukuran kinerja keuangan dan nonkeuangan dapat menjadi bagian dari sistem informasi bagi seluruh pegawai dan 
INDEXIA: Informatic and Computational Intelegent Journal

Muhammad Syaifuddin, Harunur Rosyid

Mengukur Efisiensi Kinerja Pengiriman Freeze Kontainer Dengan Menggunakan Kpi Balance

Scorecard Di Pt. Rukma Padaya Trans

tingkatan dalam organisasi. Saat ini Balance

Scorecard tidak lagi dianggap sebagai

pengukur kinerja, namun telah menjadi

sebuah rerangka berpikir dalam

pengembangan strategi.

\subsection{Pengukuran kinerja pengiriman freeze kontainer di PT. Rukma Padaya Trans}

a. Perspektif keuangan

1. Growth (berkembang) adalah tahapan awal siklus kehidupan perusahaan dimana perusahaan memiliki produk atau jasa yang secara signifikan memiliki potensi pertumbuhan yang baik.
2. Sustain (bertahan) adalah tahapan kedua di mana perusahaan masih melakukan investasi dan reinvestasi dengan mengisyaratkan tingkat pengembalian terbaik. Dalam tahap ini, perusahaan mencoba mempertahankan pangsa pasar yang ada, bahkan mengembangkannya, jika mungkin.

3. Harvest (panen) adalah tahapan ketiga di mana perusahaan benar-benar menuai hasil investasi di tahaptahap sebelumnya. Tidak ada lagi investasi besar, baik ekspansi maupun pembangunan kemampuan baru, kecuali pengeluaran

untuk pemeliharaan dan perbaikan fasilitas. Sasaran keuangan adalah hal yang utama dalam tahap ini, sehingga diambil sebagai tolak ukur, yaitu memaksimumkan arus kas masuk dan pengurangan modal kerja.

\section{b. Perspektif Pelanggan}

Mengidentifikasi segmen pelanggan dan segmen pasar dimana perusahaan akan beroperasi dan kemudian mengukur kinerja perusahaan berdasarkan target segmen tersebut

\section{c. Perspektif Proses Bisnis Internal}

1. Proses inovasi merupakan salah satu kritikal proses, dimana efisiensi dan efektifitas serta ketepatan waktu dari proses inovasi ini akan mendorong terjadinya efisiensi biaya pada proses penciptaan nilat tambah bagi pelanggan.

2. Proses Operasi merupakan proses untuk membuat dan menyampaikan produk/jasa.

3. Proses Pelayanan Purna Jual. Proses ini merupakan jasa pelayanan pada pelanggan setelah penjualan produk/jasa tersebut dilakukan

\begin{tabular}{llr} 
b. Perspektif & \multicolumn{2}{c}{ Pembelajaran dan } \\
$\begin{array}{c}\text { Pertumbuhan } \\
\text { Proses }\end{array}$ & ini & mengidentifikasi \\
infrastruktur & yang & harus dibangun \\
perusahaan & untuk & meningkatkan
\end{tabular}


INDEXIA: Informatic and Computational Intelegent Journal

Muhammad Syaifuddin, Harunur Rosyid

Mengukur Efisiensi Kinerja Pengiriman Freeze Kontainer Dengan Menggunakan Kpi Balance

Scorecard Di Pt. Rukma Padaya Trans

pertumbuhan dan kinerja jangka panjang.

Proses pembelajaran dan pertumbuhan ini bersumber dari faktor sumber daya manusia, sistem, dan prosedur organisasi

\section{Analisis Dan Perancangan Sistem}

\subsection{Analisis Sistem}

Wawancara awal dengan pihak yang terkait untuk memperoleh data di Lokasi penelitian yang dilakukan di PT. Rukma Padaya Trans yang terletak di Jalan Laksda M Nazir 29, Blok B 12 - 15, Surabaya.Barang yang dikirimkan dengan menggunakan freeze container diantaranya adalah daging, sayuran dan buah. Selama ini proses pengiriman dilakukan hanya sebatas operasional tanpa ada target untuk meningkatkan pendapatan maupun kualitas pengiriman barang di Frezee Container.

Dimana setiap pengiriman yang dilakukan tidak ada ukuran yang menggambarkan kesesuaian atau kelayakan dari container maupun ukuran dari segi pendapatan perusahaan. Berikut adalah gambaran tentang pengecheckan kondisi container baik kondisi fisik maupun kondisi alat kontrol suhu container.

\subsection{Hasil Analisis}

Analisa dari sistem yang sedang berjalan di PT Rukma Padaya Trans terbentuklah kriteria - kriteria yang dibutuhkan, maka dapat dirumuskan strategi Map untuk melihat keterkaitan antara sasaran stragi dan sasaran strategi yang terbentuk. Strategy Map merupakan suatu gambaran keterkaitan antara sasaran strategis pada tiap-tiap perspektif. Di bawah ini merupakan Strategy Map :

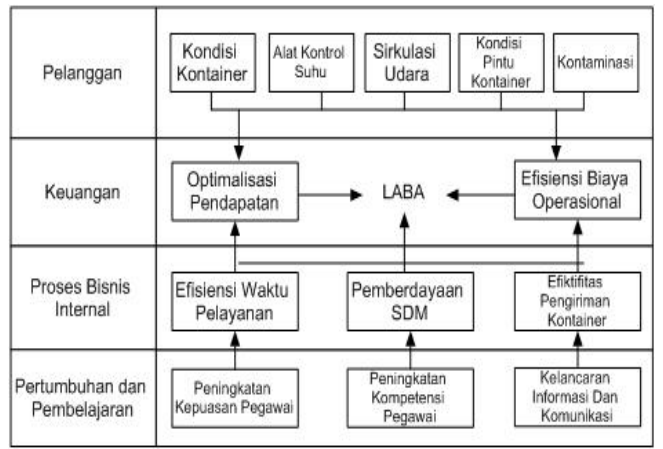

Gambar 3.2, Strategy Maps Pengukuran KPI

Pengiriman Frezee Kontainer

\subsection{Representasi Data}

Metode penelitian yang digunaan dalam mengukur Efisiensi Kinerja Pengiriman Freeze Kointainer ialah dengan meggunakan KPI Balane Scorecard dimana metode balanced scorecard sendiri dalam penyusunanya harus memperhatikan 4 (empat) perspektifif keseimbangan yaitu:

a.) Perspektif Keuangan

b.) Perspektif Pelanggan

c.) Perspektif Proses Bisnis Internal

d.) Perspektif Pembelajaran dan Pertumbuhan

Setelah itu melakukan pengumpulan data atau sesuai dengan sasaran strategi dan key performance indicator yang sudah tersusun, daftar Parameter Kinerja Pengiriman Freezer Container adalah sebagai berikut

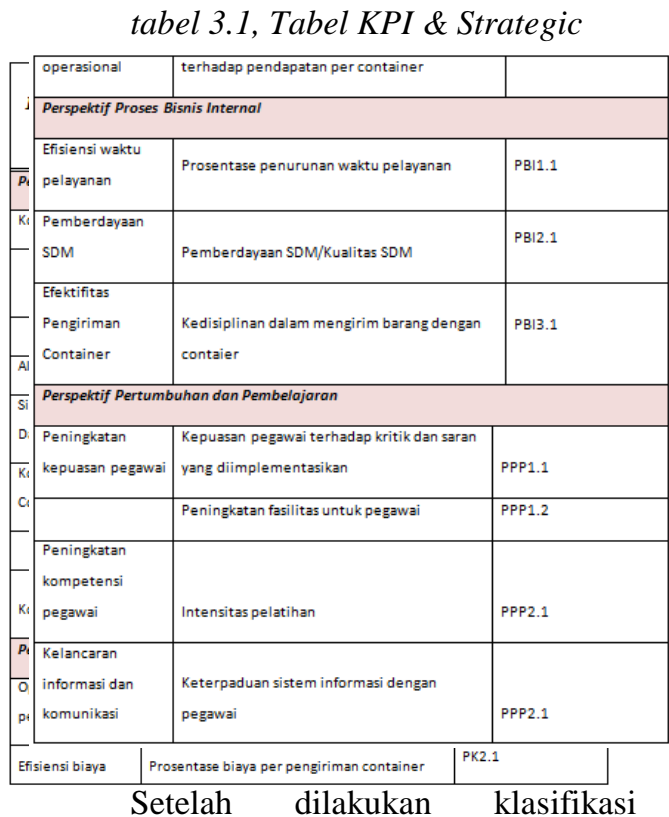

terhadap kinerja pengiriman frezee container berdasarkan perspektif balanced scorecard berikutnya melakukan pengukuran terhadap KPI (Key Performance Indicator) terhadap masing masing KPI untuk mengukur apakah kinerja pengiriman freeze container sudah memenuhi harapan perusahaan. langkahlangkah pengukuran KPI pengiriman Frezee container.

\section{1.) Menentukan Periode Penilaian KPI.}

Periode penilaian biasanya dapat diukur dengan 3 jenis pengambilan data. Yang pertama adalah pengukuran perbulan/Montly $(\mathrm{M}), \quad$ pengukuran perQuarter/ pertiga Bulan (Q) dan yang 
INDEXIA: Informatic and Computational Intelegent Journal

Muhammad Syaifuddin, Harunur Rosyid

Mengukur Efisiensi Kinerja Pengiriman Freeze Kontainer Dengan Menggunakan Kpi Balance

Scorecard Di Pt. Rukma Padaya Trans

terakhir pengukuran pertahun / pengukuran

Annual (A). berikut adalah hasil klasifikasi periode Perhitungan:

\begin{tabular}{|l|c|}
\hline \multicolumn{1}{|c|}{ Key Perfoemance Indikator } & PERIODE \\
\hline Perspektif Pelanggan & M \\
\hline Kondisi Container & M \\
\hline Alat Kontrol Suhu & M \\
\hline Sirkulasi Udara Dalam Container & M \\
\hline Kondisi Pintu Container & M \\
\hline Kontaminasi & \multicolumn{2}{|l}{} \\
\hline Perspektif Keuangan & Q \\
\hline Optimalisasi pendapatan & Q \\
\hline Efisiensi biaya operasional & Q \\
\hline Perspektif Proses Bisnis Internal & Q \\
\hline Efisiensi waktu pelayanan & Q \\
\hline Pemberdayaan SDM & \\
\hline Efektifitas Pengiriman Container & A \\
\hline Perspektif Pertumbuhan dan Pembelajaran & A \\
\hline Peningkatan kepuasan pegawai & Q \\
\hline Peningkatan kompetensi pegawai & \\
\hline Kelancaran informasi dan komunikasi & \\
\hline &
\end{tabular}

\section{2.) Menentukan Polarisasi KPI}

Polarisasi untuk perhitungan KPI pengiriman freeze container ialah (MAX) dimana semakin tinggi nilai semakin bagus pula hasil KPI dan (MIN) dimana semakin rendah Nilai semakin Bagus pula Hasil KPI. Berikut adalah polarisasi dari KPI pengiriman freeze container.

\begin{tabular}{|c|c|c|}
\hline Key Perfoemance Indikator & PERIODE & POLARISASI \\
\hline \multicolumn{3}{|l|}{ Perspektif Pelanggan } \\
\hline Kondisi Container & $\mathrm{M}$ & MAX \\
\hline Alat Kontrol Suhu & $M$ & MAX \\
\hline Sirkulasi Udara Dalam Container & $\mathrm{M}$ & MAX \\
\hline Kondisi Pintu Container & $M$ & MAX \\
\hline Kontaminasi & $M$ & MIN \\
\hline \multicolumn{3}{|l|}{ Perspektif Keuangan } \\
\hline Optimalisasi pendapatan & Q & MAX \\
\hline Efisiensi biaya operasional & $Q$ & MIN \\
\hline \multicolumn{3}{|l|}{ Perspektif Proses Bisnis Internal } \\
\hline Efisiensi waktu pelayanan & Q & MIN \\
\hline Pemberdayaan SDM & $Q$ & MAX \\
\hline Efektifitas Pengiriman Container & Q & MAX \\
\hline \multicolumn{3}{|c|}{ Perspektif Pertumbuhan dan Pembelajaran } \\
\hline Peningkatan kepuasan pegawai & A & MAX \\
\hline Peningkatan kompetensi pegawai & A & MAX \\
\hline $\begin{array}{l}\text { Kelancaran informasi dan } \\
\text { komunikasi }\end{array}$ & Q & MAX \\
\hline
\end{tabular}

3.) Menentukan Satuan dan Kalkulasi Perhitungan

Kalkulasi digunakan untuk pengambilan data yg dipergunakan untuk perhitungan Akhir biasanya untuk kalkulasi menggunakan (AVERAGE) untuk mengambil rata-rata hasil KPI perbulan, (SUM) penjumlahan setiap KPI perbulanya, (LAST) pengambilan nilai yang paling terakhir dan (MIN) pengambilan nilai KPI dengan mengurangi tiap bulanya. Sementara untuk satuan ialah aturan untuk pengukuranya bisa memakai Persen(\%),Rupiah dan sebagainya. Beriut adalah hasil kalkulasi dan satuan pengirman freeze ontainer.

\begin{tabular}{|c|c|c|c|c|}
\hline $\begin{array}{c}\text { Key Perfoemance } \\
\text { Indikator }\end{array}$ & PERIODE & POLARISASI & SATUAN & $\begin{array}{l}\text { KALKULASI } \\
\text { UP TO }\end{array}$ \\
\hline \multicolumn{5}{|l|}{ Perspektif Pelanggan } \\
\hline Kondisi Container & M & MAX & PERSEN & AVERAGE \\
\hline Alat Kontrol Suhu & M & MAX & PERSEN & AVERAGE \\
\hline $\begin{array}{l}\text { Sirkulasi Udara Dalam } \\
\text { Container }\end{array}$ & M & $\operatorname{MAX}$ & PERSEN & AVERAGE \\
\hline Kondisi Pintu Container & M & MAX & PERSEN & AVERAGE \\
\hline Kontaminasi & M & MIN & PERSEN & AVERAGE \\
\hline \multicolumn{5}{|l|}{ Perspektif Keuangan } \\
\hline Optimalisasi pendapatan & Q & MAX & RP(Juta) & LAST \\
\hline Efisiensi biaya operasional & Q & MIN & RP(Juta) & LAST \\
\hline \multicolumn{5}{|c|}{ Perspektif Proses Bisnis Internal } \\
\hline Efisiensi waktu pelayanan & Q & MIN & PERSEN & AVERAGE \\
\hline Pemberdayaan SDM & Q & MAX & PERSEN & AVERAGE \\
\hline $\begin{array}{l}\text { Efektifitas Pengiriman } \\
\text { Container }\end{array}$ & Q & $\operatorname{MAX}$ & PERSEN & AVERAGE \\
\hline \multicolumn{5}{|c|}{ Perspektif Pertumbuhan dan Pembelajaran } \\
\hline $\begin{array}{l}\text { Peningkatan kepuasan } \\
\text { pegawai }\end{array}$ & A & $\operatorname{MAX}$ & PERSEN & AVERAGE \\
\hline $\begin{array}{l}\text { Peningkatan kompetensi } \\
\text { pegawai }\end{array}$ & A & $\operatorname{MAX}$ & PERSEN & AVERAGE \\
\hline $\begin{array}{l}\text { Kelancaran informasi dan } \\
\text { komunikasi }\end{array}$ & Q & $\operatorname{MAX}$ & PERSEN & AlveraGe \\
\hline
\end{tabular}

tabel 3.4, Tabel Satucon Pengulaurcon $K P I$

4.) Menentukan Bobot Tiap KPI

Bobot KPI digunakan untuk mengukur tingkat kepentingan atau focus pekerjaan tiap tahunya. Berikut adalah hasil dari pembobotan KPI pengiriman Frezee Container.

tabel 3.5, Tabel Bobot Penguluurcon KPI

\begin{tabular}{|c|c|c|c|c|c|}
\hline $\begin{array}{c}\text { Key Perfoemance } \\
\text { Indikator }\end{array}$ & PERIODE & POLARISASI & SATUAN & $\begin{array}{c}\text { KALKULASI } \\
\text { UP TO }\end{array}$ & ВОВОт \\
\hline \multicolumn{6}{|l|}{ Perspektif Pelanggan } \\
\hline Kondisi Container & $\mathrm{M}$ & MAX & PERSEN & \begin{tabular}{|l} 
AVERAGE \\
\end{tabular} & $5 \%$ \\
\hline Alat Kontrol Suhu & $M$ & MAX & \begin{tabular}{|l|} 
PERSEN \\
\end{tabular} & \begin{tabular}{|l|} 
AVERAGE \\
\end{tabular} & $5 \%$ \\
\hline $\begin{array}{l}\text { Sirkulasi Udara Dalam } \\
\text { Container }\end{array}$ & M & MAX & PERSEN & AVERAGE & $5 \%$ \\
\hline 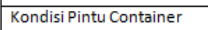 & $\mathrm{M}$ & MAX & \begin{tabular}{|l} 
PERSEN \\
\end{tabular} & \begin{tabular}{|l|} 
AVERAGE \\
\end{tabular} & $5 \%$ \\
\hline ontar & $M$ & MIN & PERSEN & AVERAGE & 5 \\
\hline
\end{tabular}


INDEXIA: Informatic and Computational Intelegent Journal

Muhammad Syaifuddin, Harunur Rosyid

Mengukur Efisiensi Kinerja Pengiriman Freeze Kontainer Dengan Menggunakan Kpi Balance

Scorecard Di Pt. Rukma Padaya Trans

4.) Menentukan Target \& Realisasi

Dari target dan actualnya maka bisa melihat bahwa PT. Rukma Padaya Trans sudah bisa mencapai target yang telah ditentukan oleh perusahaan tersbut dengan actual tersbut dibagi target yang sudah ditetapkan sebelmnya. Berikut adalah perhitungan KPI berdasarkan Target \& Realisasi pengiriman freeze Container per tahun 2018.

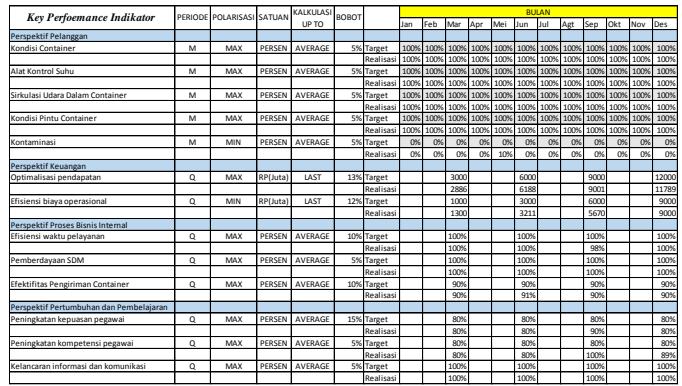

Kesimpulan :

Berikut adalah form perhitungan KPI yang diberikan target, dimana pemberian target harus mengacu pada periode pengukuran KPI, yang mana pemberian target dapat dilakukan per 3 bulan atau perbulan.
6.) Perhitungan Nilai KPI

Langkah selanjutnya adalah perhitungan KPI unit kerja berdasarkan target dan realisasi yang actual di perusahaan.pada peroses perhitugan juga harus memperhatikan bentuk POLARISASI, PERIODE, dan KALKULASI.

a.) dimana cara menghitung POLARISASI adalah dengan

Mengunakan rumus sebagai berikut:

MIN : (Target - Retalisasi ) x Bobot

MAX :(Realisasi - Target) $x$ Bobot

b.) Untuk perhitungan KALKULASI adalah pengambilan Nilai untuk perhitungan KPI. Berikut adalah penjelasan dari masing-masing atribut kalkulasi:

AVERAGE : Jumlah rata rata nilai dalam periode 1 tahun

LAST : data penilaian yang paling terakhir.

SUM : Hasil penjumlahan seluruh data KPI perbulanya

\subsection{Perancangan Sistem}

Dari Hasil Analisis sistem kemudian dilakukan perancangan sistem dari aplikasi pengukuran Efisiensi Kinerja pengiriman Freeze Kontainer dengan menggunakan KPI Balance Scorecard. Dalam merancang aplikasi sistem menggunakan beberapa fase dalam perancangan perangkat lunak sehingga menghasilkan sistem aplikasi yang terstruktur dengan Baik.

\subsubsection{Diagram Context}


INDEXIA: Informatic and Computational Intelegent Journal

Muhammad Syaifuddin, Harunur Rosyid

Mengukur Efisiensi Kinerja Pengiriman Freeze Kontainer Dengan Menggunakan Kpi Balance

Scorecard Di Pt. Rukma Padaya Trans

Berikut adalah diagram context

pada aplikasi pengukuran Efisiensi

Kinerja pengiriman Freeze Kontainer dengan menggunakan KPI Balance Scorecard di PT Rukma Padaya Trans.

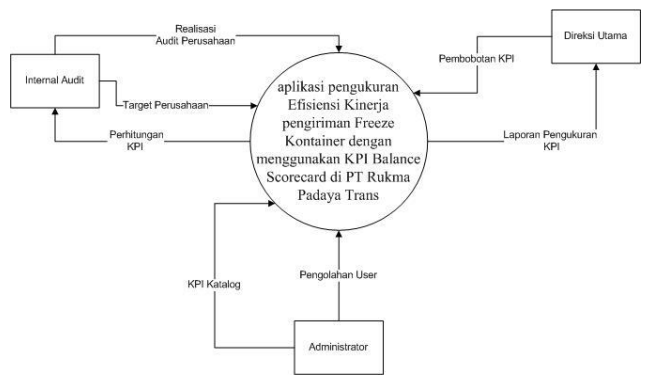

Gambar 3.5, Context Diagram Pengukuran $K P I$

\subsubsection{Diagram Hirarki}

Dalam pembuatan sistem dari aplikasi pengukuran Efisiensi Kinerja pengiriman Freeze Kontainer dengan menggunakan KPI Balance Scorecard di PT Rukma Padaya Trans diperlukan Diagram berjenjang dimna merupakan awal dari penggambaran data flow Diagram (DFD) sampai ke level-level lebih bawahnya lagi.

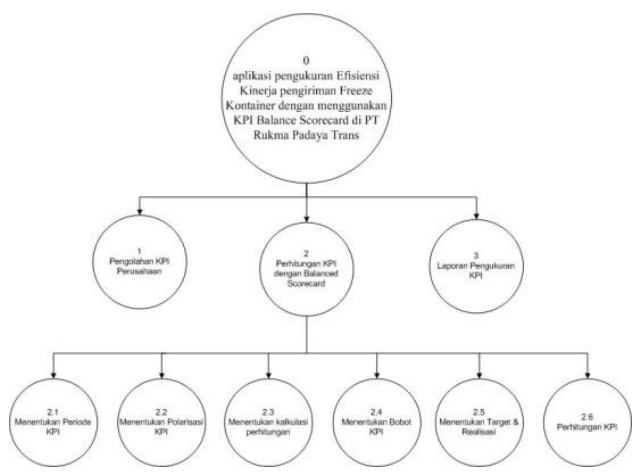

Gambar 3.6, Hirarki Diagram Pengukuran KPI

Keterangan:

Dari gambar diatas dapat dilihat bahwa aplikasi pengukuran Efisiensi Kinerja pengiriman Freeze Kontainer dengan menggunakan KPI Balance Scorecard di PT Rukma Padaya Trans terbagi menjadi 3 tingkatan diagram hirarki, dimana pada top levelnya ialah Membuat aplikasi pengukuran efisiensi Kinerja Pengiriman Freeze Kontainer.

\subsubsection{Data Flow Diagram}

Data Flow Diagram (DFD) adalah alat pembuatan model yang memungkinkan profesional sistem untuk menggambarkan sistem sebagai suatu jaringan proses fungsional yang dihubungkan satu sama lain dengan alur data, baik secara manual maupun komputerisasi.

\subsubsection{DFD Level 0}

Berikut adalah gambaran DFD levell pada sistem pengukuran kinerja pengiriman Freeze container.

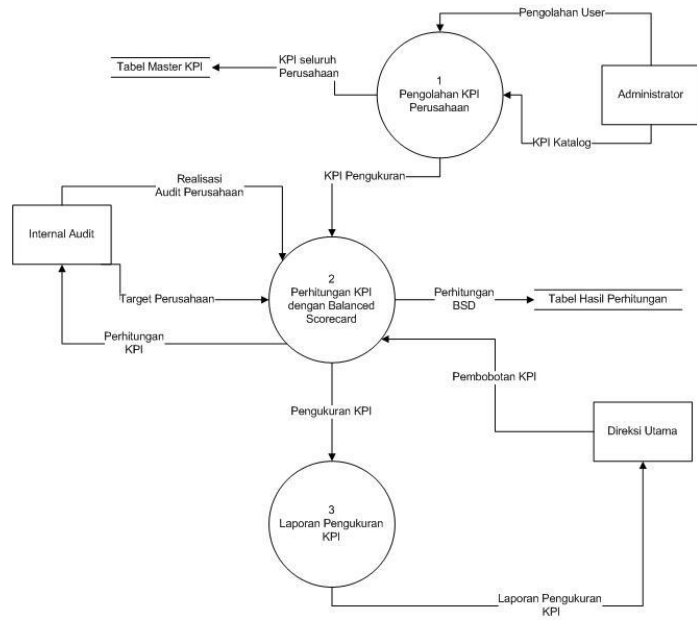

Gambar 3.7, DFD Lvl 0 Pengukuran KPI

\subsubsection{DFD Level 1}

Dari diagram hirarki diatas dapat dilihat terdapat 2 lapisan dimana lapisan 2 di diagram tersebut sebagai acuan untuk pembuatan DFD Level 1 sistem sebagai berikut :

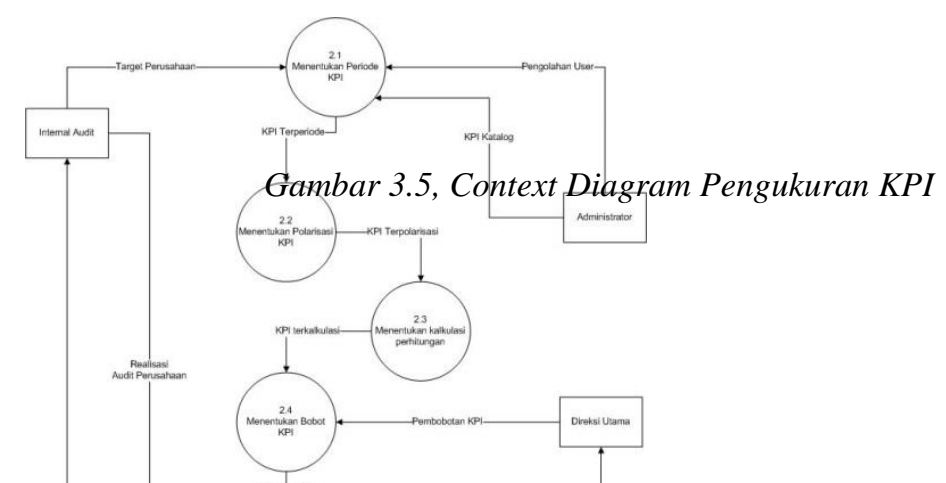


INDEXIA: Informatic and Computational Intelegent Journal

Muhammad Syaifuddin, Harunur Rosyid

Mengukur Efisiensi Kinerja Pengiriman Freeze Kontainer Dengan Menggunakan Kpi Balance

Scorecard Di Pt. Rukma Padaya Trans

Gambar 3.8, DFD Lvl 1 Pengukuran KPI

\section{Implementasi dan Pengujian Sistem}

\subsection{Implementasi Sistem}

Implementasi sistem adalah implementasi dari analisa dan desain yang telah dibuat sebelumnya. Sehingga diharapkan dengan adanya implementasi ini dapat dipahami jalanya suatusistem untuk mengukur kinerja pengiriman di PT Rukma Pandaa Trans diharapkan mampu memberikan rekomendasi terhadap perusahaan terkait bagaimana mengukur kinerja karyawan maupun unit kerjanya sehingga proses evaluasi kinerja tahunan akan lebih efektif dan efisien karna melihat dari hasil penilaian kinerja di sistem tersebut.

\subsubsection{Menu Login}

Menu login berfungsi sebagai inputan pengguna untuk masuk kedalam system pengukuran kinerja pengiriman freeze container PT Rukma Pandaya Trans. Pada halaman ini akan tampil seperti gambar 4.1 pada saat aplikasi dijalankan.
Gambar 4.1, implementas

i Login sistem pengukuran kinerja

A. Hak akses Admin

Hak Akses ini berfungsi sebagai penggolahan data dari pengguna sistem. Admin dapat mengubah atau menambahkan pengguna sistem. Serta berfungsi untuk mengelolah KPI katalog dalam sistem

B. Hak akses Audit

Hak Akses ini berfungsi untuk mengelolah target dan realisasi pengukuran kinerja atau KPI.

C. Hak akses Direksi

Hak Akses ini berfungsi untuk mengelolah bobot dan menerima hasil laporan terkait hasil pengukuran kinerja pengiriman freeze kontainer.

\subsection{Analisa Hasil Pengujian Sistem}

Pengujian sistem digunakan untuk menjalankan struktur sistem yang ada pada aplikasi sistem yang telah dibuat tiap pengujian sistem merupakan tahap dimana sistem akan berproses. Pada pengujian aplikasi ini menggunakan 13 data perspektif pengukuran kinerja di PT rukma pandaya Trans. 
INDEXIA: Informatic and Computational Intelegent Journal

Muhammad Syaifuddin, Harunur Rosyid

Mengukur Efisiensi Kinerja Pengiriman Freeze Kontainer Dengan Menggunakan Kpi Balance

Scorecard Di Pt. Rukma Padaya Trans

Sistem akan memberikan

di PT rukma Pandaa trans

rekomendasi berupa pencapaian

unit kerja di PT Rukma pandaya

trans dengan menampilkan unit

kerja mana yang memenuhi

ekspektasi dari perusahaan.

Berikut adalah tampilan dari hasil

rekomendasi sistem:

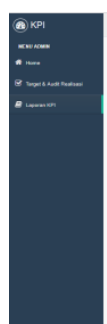

Gambar 4.2, Rekomendasi dan hasil perhitungan Kinerja

Dari gambar 4.12 diatas dapat dilihat hasil rekomendasi berupa table keterangan Memenuhi dan tidak memenuhi. Yang kemudian dri hasil tersebut di harapkan mampu memberikan rekomendari untuk perbaikan kinerja di pengiriman freeze container di PT Rukma Pandaya Trans.

\section{PENUTUP}

\subsection{Kesimpulan}

Berdasarkan hasil dari implementasi dan pengujian sistem, maka dalam penelitian tugas akhir ini dapat disimpulkan sebagai berikut:

1. Sistem ini membantu pihak audit dalam mengukur kinerja dengan mengklasifikan kinerja

sesuai dengan perspektif perspektif balanced scorecard.

2. Pada pengukuran kinerja di PT pradaya trans sangat bergantung kepada tertibnya pengisian realisasi tiap bulana oleh auditor sehingga proses pengukuran kinerja tidak lagi mengalami keterlambatan.

\subsection{Saran}

Adapun saran yang dapat diberikan kepada penelitian berikutnya apabila ingin mengembangkan sistem yang telah dibuat ini agar menjadi lebih baik adalah:

1. Untuk segi tampilan dari sistem pendukung keputusan agar lebih menarik lagi.

2. Dalam pengembangan selanjutnya disarankan untuk menambah lagi atau mempertajam dalam pembuatan KPI agar lebih spesifik dalam pengukuran kinerjanya.

3. Kedepanya diharapkan pengukuran tidak sampai unit kerja saja melainkan kinerja dari masing masing karyawan.

\section{DAFTAR PUSTAKA}

Authoni, A. Y. and E. Suryani (2014). Purwarupa Performance Dashboard Untuk Membantu Analisis Data Evaluasi Diri Perguruan Tinggi (PT) Berdasarkan Key Performance Indikators (KPI) Studi. Prosiding 
INDEXIA: Informatic and Computational Intelegent Journal

Muhammad Syaifuddin, Harunur Rosyid

Mengukur Efisiensi Kinerja Pengiriman Freeze Kontainer Dengan Menggunakan Kpi Balance

Scorecard Di Pt. Rukma Padaya Trans

Seminar Nasional Manajemen

Teknologi XXI, p. C-1-1.

Hamzah, H., et al. (2015). Sistem Pendukung Keputusan Penilaian Kinerja Dosen Dengan Metode Balanced Scorecard (Studi Kasus: Universitas Respati Yogyakarta). Seminar Nasional Informatika (SEMNASIF).

Handayani, B. D. (2011). "Pengukuran Kinerja Organisasi dengan Pendekatan Balanced Scorecard pada RSUD Kabupaten Kebumen." Jurnal Dinamika Manajemen 2(1).

Hanuma, S. and E. Kiswara (2011). Analisis Balance Scorecard sebagai Alat Pengukur Kinerja Perusahaan (Studi Kasus pada PT Astra Honda Motor), UNIVERSITAS DIPONEGORO.

Puspitasari, E. R. A. and A. ROHMAN (2014). analisis efektivitas, efisiensi, dan Kontribusi pajak dan retribusi Daerah terhadap pad kabupaten Blora tahun 2009-2013, Fakultas Ekonomika dan Bisnis.

Singgih, M. L., et al. (2004). "Pengukuran Dan Analisa Kinerja Dengan Metode Balanced Scorecard Di Pt." X"." Jurnal Teknik Industri 3(2): pp. 48-56.

Sumenge, A. S. (2013). "Analisis Efektifitas dan Efisiensi Pelaksanaan Anggaran Belanja Badan Perencanaan Pembangunan Daerah (Bappeda) Minahasa Selatan." Jurnal EMBA:
Jurnal Riset Ekonomi, Manajemen, Bisnis dan Akuntansi 1(3).

Sunarto, A. and Z. A. Hasibuan (2007). "Model Perencanaan Strategis Sistem Informasi Pada Industri Penyiaran Televisi dengan Pendekatan Blue Ocean Strategy dan Balanced Scorecard." Jurnal Sistem Informasi MTI UI 3(2): 35.

Taruna, J. K. and U. Ciptomulyono (2011). "Perancangan Sistem Pengukuran Kinerja Pada Dinas Pekerjaan Umum Daerah Kota Blitar Dengan Metode Balanced Scorecard Dan Analytical Hierarchy Process." 
INDEXIA: Informatic and Computational Intelegent Journal

Muhammad Syaifuddin, Harunur Rosyid

Mengukur Efisiensi Kinerja Pengiriman Freeze Kontainer Dengan Menggunakan Kpi Balance

Scorecard Di Pt. Rukma Padaya Trans 